\title{
Contribución al estudio de la educación superior de la República Argentina. Un recorrido a través de la Historia de la Universidad Nacional de Córdoba
}

Contribution to the study of higher education of the Argentine Republic. A journey through the History of the National University of Córdoba

Contribuição ao estudo do ensino superior na República Argentina. Uma viagem pela História da Universidade Nacional de Córdoba

María Cristina Vera de Flachs ${ }^{1}$

Universidad Nacional de Córdoba, Argentina CONICET-Grupo de investigación HISULA - UPTC

Recepción: 10/12/2018

Evaluación: 10/01/2019

Aceptación: 17/02/2019

Artículo de Investigación - Reflexión

https://doi.org/10.19053/01227238.9382

\section{RESUMEN}

Parte de este texto fue leído en el panel organizado por la Dra. Diana Soto Arango en ocasión del VI Congreso Internacional sobre Historia y Prospectiva de las Universidades de Europa y América CIHPUEA), realizado en Tunja del 10 al 12 de octubre de 2016. El objetivo de aquel encuentro era contribuir a mirar la historia de las universidades argentinas haciendo hincapié en lo ocurrido en la Universidad Nacional de Córdoba a lo largo de su historia. Teniendo en cuenta el título del mismo y considerando la am- plitud del periodo de estudio, desde la fundación de la universidad hasta nuestros días, acotamos el mismo a la construcción de su marco legal y la agenda durante las últimas décadas del siglo XX. Se utilizaron fuentes primarias, ubicadas en los archivos de la Universidad de Córdoba, colecciones de prensa, bibliografía específica y mis propias investigaciones. Metodológicamente el trabajo parte de una revisión crítica de lo realizado hasta ahora, que pretende caracterizar con sus correspondientes particularidades los di-

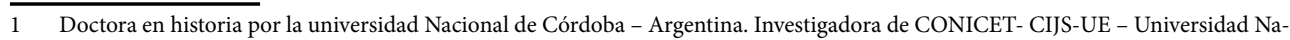
cional de Córdoba- investigadora del grupo HISULA de la Universidad Pedagógica y Tecnológica de Colombia. Correo electrónico: vera@onenet.com.ar. El articulo se vincula al proyecto de investigación "La Universidad en los desafios del siglo XXI" SGI 1965, desarrollado por el grupo HISULA, y financiado por la Vicerrectoría de investigaciónes de la UPTC. 
ferentes momentos históricos analizados. La elección de los textos se hizo siguiendo el criterio simple de tratar de arrojar luz sobre las temáticas que hemos abordado, de manera tal que el material sirva como referencia en distintas líneas de pensamiento.

Palabras clave: Universidad; Córdoba; reforma; educación superior.

\section{ABSTRACT}

Part of this text was read in the panel session organized by Dr. Diana Soto Arango on the occasion of the VI International Congress on History and Prospective Studies of the Universities of Europe and America CIHPUEA), held in the city of Tunja from 10 to 12 October, 2016. The aim of the congress was to contribute to revisit the history of Argentine universities, with special emphasis on the history of the National University of Córdoba. Taking into account the title of this work and considering the broad period of study, from the founding of the university to its current situation, we limit ourselves to the study of the construction of its legal framework and its agenda during the last decades of the twentieth century. Primary sources were used, some of them located in the archives of the University of Córdoba, press collections, specific bibliography, and my own previous research work. Methodologically, the work starts from a critical review of what has been done so far and aims to characterize the different historical moments analyzed with their corresponding particularities. The choice of texts was made following the simple criterion of trying to illuminate the topics we have addressed previously so that the material serves as a reference in different lines of thought.

Keywords: University; Córdoba; reform; higher education.

\section{RESUMO}

Parte deste texto foi lido no painel organizado pela Dra. Diana Soto Arango por ocasião do VI Congresso Internacional de História e Prospectiva das Universidades da Europa e América CIHPUEA, realizado em Tunja de 10 a 12 de outubro de 2016. O objetivo desse encontro foi contribuir para o estudo da história das universidades argentinas, enfatizando o que aconteceu na Universidade Nacional de Córdoba ao longo de sua história. Tendo em conta o título da mesma e considerando a amplitude do período de estudo, desde a fundação da universidade até aos nossos dias, limitamos o mesmo à construção do seu quadro legal e agenda durante as últimas décadas do século XX. Foram utilizadas fontes primárias, localizadas nos arquivos da Universidade de Córdoba, coleções de imprensa, bibliografia específica e minha própria pesquisa. Metodologicamente, o trabalho parte de uma revisão crítica do que foi feito até então, que visa caracterizar os diferentes momentos históricos analisados com suas correspondentes particularidades. A escolha dos textos foi feita seguindo o simples critério de tentar esclarecer as questões que abordamos, de modo que o material serve de referência em diferentes linhas de pensamento.

Palavras-chave: Universidade; Córdoba; reforma; Educação superior.

\section{INTRODUCCIÓN}

Parte de este texto fue leído en el panel organizado por la Dra. Diana Soto Arango en ocasión del VI Congreso Internacional sobre Historia y Prospectiva de las Universidades de Europa y América CIHPUEA), realizado en Tunja del 10 al 12 de octubre de 2016. Para cumplir los estándares de publicación, el texto fue 
revisado y se incluyeron notas de pie de página y las referencias bibliográficas correspondientes.

El objetivo de aquel panel se centró en revisar la historia de las universidades argentinas haciendo hincapié en lo ocurrido en la Universidad Nacional de Córdoba a lo largo de su historia. Teniendo en cuenta el título del mismo y considerando la amplitud del periodo de estudio, desde la fundación de la universidad hasta nuestros días. En un intento por hacer un relato acotado, tuvimos en cuenta la construcción de su marco legal y la agenda a partir de las últimas décadas del siglo $X X$.

Muchas preguntas podrían plantearse al estudiar un periodo tan prolongado y no las desconocemos, sin embargo, en esta ocasión nos limitamos a las siguientes: ¿cómo eran sus saberes y cuál era el modelo de universidad en el periodo anterior y posterior a la reforma de 1918?, ¿cuáles fueron los acontecimientos socio políticos que a lo largo del siglo XX incidieron para que la Universidad argentina mostrara periodos de crisis y modificara sus normativas?, ¿cuál fue el modelo de universidad en tiempos de dictadura?, ¿qué cambios hubo con el regreso a la democracia y cuáles fueron las consecuencias de las políticas neoliberales de los noventa?, ¿qué motivos incidieron en el siglo XXI para la fundación de nuevas universidades en el país?, y por último, ¿cuál es la agenda de la educación superior en dicho siglo?

La recolección de la información se basó en fuentes primarias ubicadas en los archivos de la Universidad de Córdoba, colecciones de prensa, bibliografía específica, e investigaciones previas de mi autoría. Metodológicamente, el trabajo parte de una revisión crítica de lo realizado hasta ahora e intenta caracterizar, con sus correspondientes particularidades, los diferentes momentos históricos analizados. La elección de los textos siguió un criterio simple, el de tratar de arrojar luz sobre las temáticas abordadas anteriormente de tal manera que el material sirva de referencia en distintas líneas de pensamiento.

\section{Breve esbozo histórico sobre la universidad argentina y su relación con el gobierno y la sociedad}

Para quienes no están al tanto de lo ocurrido en mi país respecto a la educación superior, ofreceré a continuación un breve esbozo histórico sobre ella. Deseo recordar que Córdoba, ciudad mediterránea, fue el centro geográfico e intelectual del virreinato del Río de la Plata y zonas adyacentes durante la época colonial. Pocos años después de la fundación de la ciudad en el siglo XVI, los jesuitas fundaron en 1613 la Universidad, primera casa de altos estudios del actual territorio argentino hasta comienzos del siglo XIX. La misma estuvo bajo su dirección hasta su expulsión, pasó entonces a manos de los franciscanos hasta 1807, luego del clero secular, y después de la independencia, en 1810, dependió del gobierno provincial y a partir de 1854, del Estado nacional, gozando en todas sus épocas de brillo y prestigio. El poeta cordobés Arturo Capdevila sintetizó la importancia de esta casa de altos estudios al decir: 
"La Universidad es historia... historia desde la hora misteriosa como lo es toda hora de súbita inspiración, en que el Obispo Trejo y Sanabria resolvió fundar en aquel caserío una casa de altos estudios. Oro no había. Plata tampoco, ni otro metal codiciable. Habría, en cambio, para todo el curso de los tiempos, oro y plata en la minería de los espíritus"2.

El modelo de la universidad argentina, en los inicios del siglo XIX, fue el propuesto por Wilhem von Humboldt para la universidad de Berlín, y adoptado luego por otras universidades germanas, que se diferenciaba del modelo francés o napoleónico, y destacó por ser formadora de profesionales dedicados a un saber-hacer. El modelo alemán colocaba a la universidad como el vehículo apropiado para desarrollar el ideal humanista y tendría por función asegurar el tránsito entre la educación formal y sistemática hacia el cultivo de la ciencia ${ }^{3}$. Así, la universidad se transformaba no en un centro de enseñanza sino de investigación, lo que suponía en el proceso de formación una relación estrecha y de mutua colaboración entre el estudiante y el profesor.

Ese modelo se reflejó en la historia de la universidad en tiempos de las presidencias de Domingo F. Sarmiento y Nicolás Avellaneda. Provincia y Universidad de Córdoba tuvieron un gran impulso como lo demuestra la inauguración, en 1870, del Observatorio Astronómico Nacional, primero en la Argentina y en el hemisferio austral, y la creación de las Facultades de Medicina y la de Ciencias Exactas, Físicas y Naturales, así como la inauguración de la Academia Nacional de Ciencias. Destacados científicos extranjeros, particularmente de procedencia alemana, llegaron en ese tiempo desarrollando importantes investigaciones relacionadas con la mineralogía, geología, zoología o botánica. En un corto lapso cambió el perfil académico de la universidad, ahora con predominio de las ciencias experimentales, al mismo tiempo que se recibía el influjo del liberalismo político y el positivismo filosófico ${ }^{4}$.

Entretanto, el 12 de agosto de 1821 se fundó la Universidad de Buenos Aires. En respuesta al crecimiento que experimentaron las dos universidades existentes en esa etapa, el 25 de junio de 1885 se promulgó la ley 1597, conocida como la ley Avellaneda ${ }^{5}$, que propició una fuerte dependencia del poder ejecutivo nacional respecto a la elección del rector y los profesores titulares que eran escogidos de una terna que conformaba el Consejo Superior y cada Consejo Directivo de las respectivas facultades, esto cada vez que fuera necesario cubrir una vacante. En consecuencia, la precaria autonomía de esas universidades se vio resentida

2 Arturo Capdevila, Córdoba del recuerdo, Colección Austral, (Córdoba, 1923).

3 B. Clark, Las universidades modernas: espacio de investigación y docencia, Miguel Ángel Porrúa, (México, UNAM, 1997).

4 Nos ocupamos del tema en varios trabajos: Cfr. María Cristina Vera de Flachs, Una emigración intelectual: los alemanes de la Universidad Nacional de Córdoba. Centro de Estudios Genealógicos de Córdoba. 4 de septiembre de 1993. "La producción científica de docentes e investigadores alemanes de la Universidad de Córdoba" en Actas de las Novenas Jornadas de Historia del Pensamiento Científico Argentino, FEPAI, Buenos Aires, 2000. "Reformas y contrarreformas y movimientos estudiantiles en la Universidad de Córdoba, 1870-1936", en Renate Marsiske (Coordina.) Movimientos estudiantiles en la historia de América Latina, III, Universidad Nacional Autónoma de México, México, 2006. María Cristina Vera de Flachs y Norma Riquelme, "Las ciencias y el evolucionismo en el pensamiento de Sarmiento", en Boletín de la Facultad de Filosofía y Humanidades, (Universidad Nacional de Córdoba, 1989).

5 La ley 1597 en Anales de la legislación argentina 1881-1888, (Buenos Aires, ediciones La ley, 1888). 
en los años subsiguientes y no tardó en ser cuestionada. Sin embargo, la ley mantuvo su vigencia hasta 1947.

\section{La universidad debe "vestir a la moda"}

El proceso de secularización que ocurrió en otras universidades latinoamericanas, se sintió en Córdoba tardíamente, y ello se debía a que sectores conservadores detentaban el gobierno universitario, aunque el ambiente denunciaba una necesidad de cambio. Los intelectuales y egresados de ese tiempo conformaban una elite con clara conciencia de grupo y pertenencia a un estrato para el cual estaban reservadas las altas funciones del gobierno, no obstante, muchos comenzaron a cuestionar la institución señalando que la misma debía vestir a la moda.

Para fines de esa centuria un exalumno y pensador, el Dr. Ramón J. Cárcano, compenetrado desde hacía largos años de la urgencia de realizar una reforma escribió, en 1892, un libro titulado La Universidad de Córdoba, donde señaló que esta podía adoptar el modelo de organización de las universidades alemanas, basándose en lo observado en su viaje a Europa ${ }^{6}$. Su propuesta contemplaba desde la autonomía hasta la enseñanza gratuita y la elección democrática del rector. Los reclamos se hacían sentir también en la prensa; en un artículo aparecido en ese tiempo en un periódico bien mordaz se decía que:

"la Universidad de Córdoba necesitaba vestirse a la moda, y aunque de ella hayan salido los hombres más expectables que tiene el país, sin embargo no es propio, dado el gusto moderno que ella continúe regenteada por hombres que solo enseñan preocupaciones, fanatismos e ideas antediluvianas... ;Fuera entonces todos los retrógrados que quieren hacer conocer a Dios antes que a la naturaleza!

Esto dio motivo a que otros actores hablaran de la necesidad de efectuar cambios; por ejemplo, Osvaldo Magnasco, ministro de educación del presidente Julio A. Roca, en 1899 y desde los mismos estrados de la Universidad de Córdoba refiriéndose a las universidades dijo:

"Las instituciones son al fin formaciones de orden moral y tienen que adquirir -o languidecen o mueren- la consistencia y morfología misma que quiere darles el medio que las nutre"s.

Y a continuación presentó un proyecto de ley titulado Plan de Instrucción General y Universitaria que, aunque bien fundado, no tuvo éxito. Estas primeras reformas no tuvieron acogida pues eran impuestas desde arriba. Esto nos anima a preguntarnos ¿Cómo se veía en Córdoba la enseñanza universitaria a comien-

\footnotetext{
6 Ramón J. Carcano, La Universidad de Córdoba. Algunas palabras sobre su organización, (Buenos Aires, Félix Lajoune, 1892 ), 24 y 25.

7 La Carcajada, periódico cordobés, 5 de junio de 1881, 5.

8 Véase el texto completo en Diario de Sesiones de la Cámara de Diputados, 1899, 641-652.

https://www.cadal.org/documentos/Documento_147.pdf
} 
zos del siglo XX? Los acontecimientos internacionales, como la Primera Guerra Mundial y la Revolución Rusa, plantearon nuevos problemas y eso llevó a los intelectuales y a los jóvenes a reflexionar sobre el mundo del momento. Europa dejaba de ser vista como meta y América comenzaba a expresar la necesidad de ser el relevo del viejo mundo. Intelectuales de la talla de José Enrique Rodó, Rubén Darío, José Martí y el mismo Deodoro Roca señalaban el fin de los valores y moral europeos sobre el mundo americano y pensaban en una renovación 9 .

En los últimos meses de 1917, los jóvenes cordobeses abandonaron su rol pasivo y reclamaron el derecho a ser protagonistas de la vida universitaria solicitando la actualización de contenidos programáticos, y el ingreso de nuevas corrientes de pensamiento, temas que venían reiterando desde tiempo atrás sin obtener respuestas concretas. Pero esta vez el ambiente se complicó a raíz que, desde distintas vertientes y en diferentes momentos, muchos expusieron sus concepciones acerca de la necesidad de efectuar trasformaciones. Evidentemente querían un cambio de los viejos sistemas de enseñanza en los que se advertía el resabio colonial, que en Córdoba significaba el predominio de lo eclesiástico y el influjo teocrático y teológico, lo que explica que los gritos de los jóvenes en las calles de Córdoba fuera Frailes, no. Ser reformista implicaba ser laicista. Por entonces el estudiantado tenía un enemigo común; el clericalismo y el antiimperialismo.

\section{El contexto socioeconómico de la Argentina en 1918 y la Reforma Univer- sitaria}

Para 1918 la República Argentina estaba entre los primeros ocho países del mundo y el primero en América latina respecto al estado de su educación. Contaba con tres universidades nacionales: la de Córdoba, la de Buenos Aires (establecida en 1821) y la de La Plata (el 19 de agosto de 1905) y una provincial de reciente creación, la de Tucumán (instituida el 25 de mayo de 1914) y la propuesta de los jóvenes para que se crease otra casa de altos estudios en el Litoral. Ese año los estudiantes decidieron actuar y como primera medida, el 11 de abril, fundaron la Federación Universitaria Argentina y el 15 de junio, sentaron las bases de lo que se conoce como la Reforma Universitaria, donde se planteó la centralidad del estudiante, abogando por la asistencia libre, periodicidad de cátedra, publicidad de los actos universitarios, extensión y ayuda social a los educandos, la renovación del currículo y la autonomía que surge como repuesta a la intromisión política de los gobiernos sobre la institución.

Sin embargo, en mi opinión, el legado más vivo de la reforma fue pensar la Universidad. Ir contra prejuicios, dogmas y extender los progresos científicos para ponerlos al alcance de todos. Proclamar nuevos ideales de libertad, una democracia libre de fraudes, tender una mano a la clase obrera y crear una con-

9 Deodoro Roca configuró una definición del intelectual como guía de la juventud. Como gran parte de los pensadores de su generación, Roca unía irremediablemente el antiimperialismo con la revolución social. Cfr. Néstor Kohan, Deodoro Roca, el hereje, selección y estudio preliminar, (Buenos Aires, Editorial Biblos, 1999), 59-104. 
ciencia en las juventudes de América que enfrentara y resolviera los problemas con un carácter revolucionario, lo que suponía una acción antiimperialista en el plano económico y cultural.

Uno de los principales adalides de la reforma de 1918, Deodoro Roca, sostenía en el Manifiesto Liminar que:

“...en la Universidad está el secreto de la futura transformación. Ir a nuestras universidades a vivir, no a pasar por ellas... Probablemente la organización de los pueblos se realizará conforme al tipo de una cierta universidad, que todavía no hemos delineado, pero al que se aproximan mucho las universidades americanas: es necesario ponerse en contacto con el dolor, con la esperanza del pueblo, ya sea abriéndole las puertas de la Universidad o desbordándola sobre él. Así, al espíritu de Nación lo hará el espíritu de la Universidad"10.

\section{El difícil tiempo nuevo}

En poco tiempo, la reforma de Córdoba de 1918 y el programa propuesto recorrió diez países americanos, mientras en Córdoba, su ciudad bautismal, la contrarreforma hacía su aparición. Pronto se volvieron a oír los discursos estudiantiles que volvían a reclamar una universidad moderna, al tiempo que la Federación Universitaria de Córdoba se convertía en el brazo que movilizó las huelgas estudiantiles de 1923, 1924, 1928, y 1932.

Cuando en setiembre de 1930 estalló el primer golpe de Estado en la Argentina, el estudiantado paradójicamente acompañó en un comienzo al mismo; aunque pronto se dieron cuenta de su error cuando comprobaron las primeras persecuciones ideológicas y los despidos de docentes reformistas. Por eso, Deodoro Roca plantea la necesidad de la politización del movimiento reformista y, trazando el camino para ese "difícil tiempo nuevo", sostiene que la lucha debía ser democrática y antifascista. Con gran lucidez, previendo lo que iba a ocurrir en años posteriores en el país, aseguró:

La aventura de septiembre restablece, inesperadamente lo peor de la tradición militar del país. Nos southamericaniza en el nefasto sentido de la palabra. Claro que el Ejército, propiamente, no gobernará; pero no se podrá ya prescindir de él en nuestra vida política. Y se corromperá cada vez más. Y servirá -quién sabe hasta cuándopara los peores menesteres. En vez de servir a los fines democráticos que justificaron su creación, en vez de ser una fuerza organizada para defender la integridad de la Patria y el afianzamiento de su libertad con los valores de civilidad y justicia que sólo ella puede asegurar, será -cada vez más- en lo exterior un peligro, y en lo interior un instrumento de opresión, amparo del privilegio y de la iniquidad" 11.

10 "El Manifiesto Liminar", en La Gaceta Universitaria, Córdoba, viernes 21 de junio de 1918, año I, nro. 10, 5. Veáse un estudio sobre el movimiento estudiantil de Diana Elvira Soto Arango; José Antonio Rivadeneira; Jorge Enrique Duarte Acero y Sandra Liliana Bernal Villate, La generación del movimiento estudiantil en Colombia. 1910-1924. Revista Historia de la Educación Latinoamericana, 20 , no. 30, (2018): 217-241. doi.org/10.19053/01227238.8056

11 Revista Flecha, Córdoba, 15 de junio de 1936. Deodoro Roca, El difícil tiempo nuevo, (Edit. Lautaro, Buenos Aires, 1956), 55. 


\section{La educación superior hacia la segunda mitad del siglo XX}

La década de los cuarenta hasta la mitad de los cincuenta la política universitaria argentina estuvo dominada por el peronismo, caracterizado sobre todo en sus últimos tiempos por fuertes matices autoritarios y por la presencia de una oposición cada vez más combativa ${ }^{12}$.

Eso cambió drásticamente en la entre 1956 y 1966 cuando la universidad estuvo marcada por la modernización y el desarrollo. En ese periodo, su gestión está ligada al proceso de institucionalización de las Ciencias Sociales y al surgimiento de un pensamiento social latinoamericano. Grandes intelectuales como Risieri Frondizi, Raúl Prebisch, y Gino Germani; en Argentina o Darcy Ribeiro; en Brasil fueron los impulsores de una universidad cuya misión social debía realizar una transformación radical de las antiguas estructuras sociales, políticas, y culturales del continente ${ }^{13}$. Ese período es considerado por muchos como la época de oro de las universidades argentinas, pero pronto concluiría.

\section{Una etapa difícil}

El cierre de esa etapa se produce en las décadas del sesenta y setenta cuando Latinoamérica y Argentina sienten grandes convulsiones a raíz del advenimiento de las dictaduras militares, lo que trajo como consecuencia el cierre de una etapa y el inicio de tremendos problemas para la educación superior.

Los jóvenes tomaron su puesto como ciudadanos en la vida política y en sus demandas hablaban ahora de socialismo, revolución, y expulsión del imperialismo en todas sus formas y de las oligarquías asociadas al capital extranjero. Pero no por ello dejaron de dar batalla a temas estrictamente académicos, reclamando por el atraso que mostraban ciertas cátedras ${ }^{14}$. En ese clima de protesta se unieron a la clase obrera para cuestionar el orden político dictatorial. La unión con ese sector era imprescindible, particularmente en Córdoba donde en los años 50 se habían instalado varias industrias automotrices y las Industrias Aeronáuticas y Mecánicas del Estado. El debate universitario planteaba la antinomia entre la universidad de los trabajadores del pueblo y la universidad científica o universidad de la excelencia. "Dicho de otro modo; calidad o inclusión"15.

12 Norma Dolores Riquelme, se ocupó del tema en "Conformación de espacios de poder en el gobierno de la Universidad Córdoba (Argentina) a mediados del siglo XX”, Revista Historia de la Educación Latinoamericana, vol. 11, (2008):167 a 188. Daros, W. Incidencias del proceso histórico en el proceso educativo argentino. Revista Historia de la Educación Latinoamericana, vol. 16 no. 22 (2014): 51-84. https://doi.org/10.19053/01227238.2689

13 Para los interesados Cfr. Risieri Frondizi, La universidad en un mundo de tensiones. Misión de las universidades en América Latina, (Editorial Paidós, Buenos Aires 1971). Darcy Ribeiro, La Universidad latinoamericana. (CEAL, Universidad de la República, Montevideo, 1968).

14 Respecto a la politización del estudiantado ver entre otros a Beatriz Sarlo, La batalla de las ideas 1943-1973, Biblioteca del pensamiento argentino, VII, Emecé, (Buenos Aires 2007), 87 a 91. Alejandra Gómez, No nos han vencido..., Historia del Centro de Estudiantes de Derecho UBA, Librería del Centro de Estudiantes, (UBA, Buenos Aires, 1994).

https://www.amazon.es/No-nos-han-vencido-Estudiantes/dp/987950450X

15 Palabras de Carolina Scotto, rectora de la Universidad de Córdoba en Estela M. Miranda (coordinadora), Democratización de la educación superior. Una mirada a 400 años de la Universidad en la región. I Seminario de Democratización de la educación superior. Una mirada desde el MERCOSUR, (Editorial de la Universidad Nacional de Córdoba, Córdoba, 2014), 8. 
Entretanto, el crecimiento de la población estudiantil universitaria fue considerado como uno de los problemas socialmente más relevantes. A partir del diagnóstico de superpoblación estudiantil se puso en marcha el Plan Taquini ${ }^{16}$. La universidad de masas en contraposición con la universidad científica fue uno de los principales factores que motivó el desarrollo del Plan. El aumento sostenido de la matrícula, en todas las universidades del país, era incompatible con una universidad científica que debía velar por el desarrollo y el progreso.

Para descentralizar, entre 1971 y 1973, se crearon 13 universidades y se nacionalizaron algunas provinciales lo que posibilitó que, en 1975, Argentina contase con un total de 47 universidades nacionales, número que se mantendrá estable hasta 1989.

En 1976 se produjo un nuevo golpe de Estado. Entre esa fecha y 1983 el modelo universitario se caracterizó por la intervención directa del gobierno militar con rectores y decanos interventores, control ideológico, político y educativo. La ley 21276 de 1976 consagró y subordinó las universidades al control del Estado ${ }^{17}$. Entre otras cosas, se establecíó que "quedaba prohibida, en el recinto de las universidades, toda actividad que asumiera formas de adoctrinamiento, propaganda, proselitismo o agitación de carácter político o gremial, docente, estudiantil y no docente". La consecuencia de esta política universitaria fue un descenso abrupto de la matrícula, aplicación de aranceles, cupos de ingreso, reducción del financiamiento universitario. A la vez se estableció un sistema represivo contra todos los que tuvieran ideas distintas al régimen, lo que provocó centenares de víctimas y numerosos exiliados entre sus docentes y estudiantes. Dicha política originó una época de violencia donde hubo obreros, docentes y estudiantes desaparecidos o privados de su libertad y mucho fanatismo de parte de los grupos guerrilleros. Los crímenes de la derecha y de la izquierda causaron mucho daño al país y a la universidad argentina.

En síntesis, los reiterados quiebres políticos y la inestabilidad institucional que sufrió Argentina en el último cuarto de siglo XX incidió para que las universidades públicas sintieran cambios y retrocesos, y se desfinanciaran.

\section{El regreso de la democracia y un nuevo clima político y social en Argentina}

A partir de los años 80, en el marco de la apertura económica y el regreso a la democracia, los Estados latinoamericanos elaboraron distintas respuestas ante el aumento de la demanda de la educación superior en vinculación con la globalización económica; entre ellas la diversificación de fuentes de financiamiento,

16 El Plan Taquini nació en 1968, ideado por el Dr. Alberto Taquini (h), junto con sus colaboradores, los doctores Enrique Urgoiti y Sadi Rifé. El primer esbozo de proyecto de nuevas universidades fue presentado en el Coloquio sobre Modernización de las Instituciones Políticas en la Argentina, organizado por la Academia del Plata, en Chilecito, La Rioja. Esa política lograría expandir (descentralizar) la población universitaria juvenil, y hacer eco en la problemática cultural, científica y tecnológica de las diferentes zonas geográficas.

Alberto Taquini, Enrique Urgoiti, Sadi Rifé Nuevas Universidades para un nuevo país, (Ángel Estrada y Cía. S. A. Editores, Buenos Aires, 1972). Augusto Pérez Lindo, Universidad, politica y sociedad. (Editorial Eudeba, Buenos Aires, 1986).

17 Publicada en Boletín Oficial 06/04/1976 - ADLA 1976 - B, 1041. Consultado en línea en 2016. www.der.unicen.edu.ar/uploads/resoluciones/Leyes/Decley_21276.pdf. 
reformas curriculares, expansión de las universidades privadas, actualización docente, y promoción de carreras no tradicionales orientadas al mercado. Para Claudio Rama, este sería el periodo de la segunda reforma ${ }^{18}$.

En 1983, la República Argentina comienza a transitar el camino hacia la democracia, y concomitantemente se produce la normalización de la vida universitaria. Para la Universidad de Córdoba, como para tantas otras nacionales, eso significó que se reincorporaran docentes que, por distintas razones, en su mayoría políticas, se habían alejado de las aulas. Paralelamente se llamaron a concurso las cátedras que habían quedado acéfalas.

Durante los años noventa, la implementación de las políticas neoliberales se extendió ampliamente por territorio sudamericano, contando con el apoyo de los organismos financieros, en especial del Fondo Monetario Internacional (FMI) y el Banco Mundial (BM), lo que dejó un saldo lamentable para el crecimiento económico, el trabajo, la salud y el bienestar de millones de argentinos. Esas instituciones tuvieron un rol capital en el diseño de programas destinados a la reformulación de los sistemas educativos de la región, en ámbitos tales como la escuela primaria, la secundaria y el nivel universitario.

En consecuencia, en la Argentina el 20 de julio de 1995 se sancionó una nueva Ley de Educación Superior (LES) No. 24501 que regulaba el sistema universitario $^{19}$. La política de mejorar la calidad académica dejaba de lado la intervención en las carreras de grado, para promocionar la oferta de los posgrados y maestrías, que comienzan a proliferar en el ámbito universitario ${ }^{20}$.

La ley tuvo resistencia y el movimiento estudiantil y docente elevaron, en reiterados encuentros, voces de protesta; en tanto consideraban que esta ley contradecía los postulados de la Reforma de 1918. Por ende, volvían a reclamar por una universidad científica, gratuita, laica y pública, rechazando la equiparación de los títulos de las universidades públicas y privadas, y solicitando se garantizara la capacitación docente gratuita y la participación de los estudiantes en los concursos docentes.

En este contexto, los años 90 trajeron dos novedades al escenario universitario argentino: por un lado, un conjunto de políticas de reforma de corte centradas en la lógica de la evaluación, la acreditación y la distribución del financiamiento a través de programas especiales que, a la vez que replanteaban las relaciones entre Estado y universidad, avivarán diversos planteos críticos y conflictos en la educación superior. Por otro, la creación de un gran número de nuevas universidades; muchas de ellas con formatos de gobierno hasta cierto punto innovadores respecto de los modelos organizacionales más clásicos.

18 María Cristina Vera de Flachs y Teresa de Sierra, "Similares agendas de políticas educativas de dos universidades latinoamericanas: UNC Y UNAM y sus efectos en la consolidación de nuevas identidades, Cuadernos del CIAN, (Universidad Carlos III de Madrid, 2012). Claudio Rama, La nueva reforma de la diversidad universitaria: de la diferenciación institucional a la diversidad educativa, es.slideshare.net/claudiorama/la-nueva-reforma-de-la-diversidad-universitaria

19 La ley fue sancionada: 20 de julio de 1995 y promulgada: 7 de agosto de ese año (Decreto 268/95) Publicada el 10 de agosto de 1995 (Boletín Oficial Nro. 28.204). Se ocuparon del tema entre otros María Alaniz y otros, en "Las reformas educativas en las universidades públicas" en Movimientos estudiantiles en América y Europa, Córdoba, Junta Provincial de Historia de Córdoba, Báez Ediciones, 2006, Tomo II, 351 y ss.

20 Ver Marcela Mollis, La universidad argentina en tránsito. Ensayo para jóvenes y no tan jóvenes, FCE, (Buenos Aires, 2001). 


\section{La universidad en el siglo XXI}

La crisis económica, política e institucional que padeció Argentina en el año 2001 dio inicio a nuevos planteos. El ajuste del presupuesto educativo, en un $40 \%$, impactó en el financiamiento de la enseñanza universitaria. El debate señalaba que era el Estado el que sostenía la educación superior, pero a la vez, se insistía en la necesidad de buscar otros recursos que no intervinieran la libertad académica y respetaran su autonomía.

Paralelamente, volvieron a hacerse oír las quejas sobre la sanción de la ley de Educación Superior de 1995. Durante el gobierno de Cristina Fernández de Kirchner, impulsada por la senadora Adriana Puiggrós. En junio de 2013 se presentaron modificaciones a la misma que fueron sancionadas el 28 de octubre de 2015 como ley 27204 de implementación efectiva de la responsabilidad "indelegable y principal del Estado en el nivel de educación superior", considerándola un "bien público" y un "derecho humano"21.

La reforma explicitaba que ningún ciudadano puede ser privado del acceso a la Universidad por razones personales o de origen social y hace cargo al Estado de garantizar ese derecho. Uno de los principales cambios es la incorporación del artículo 2 bis, que explicita que las carreras de grado en las universidades públicas son gratuitas y decreta "la prohibición de establecer sobre ellos cualquier tipo de gravamen, tasa, impuesto, arancel o tarifa directa o indirecta".

Para entonces, pocas universidades públicas cobraban aranceles optativos, solo lo hacían la Universidad Tres de Febrero en la provincia de Buenos Aires y la de Córdoba en algunas carreras hasta 2011. Pero la ley cierra la posibilidad de hacerlo en el futuro. La modificación establece, además, que "el Estado Nacional es el responsable de proveer el financiamiento, la supervisión y fiscalización de las Universidades Nacionales y de las Privadas".

La nueva norma garantizaba que fuesen "las provincias y la Ciudad Autónoma de Buenos Aires las responsables de proveer el financiamiento, la supervisión y fiscalización" de los Institutos de Formación Superior de sus distritos y casa de altos estudios provinciales, si las tuviere.

Por otra parte, estableció el acceso a la universidad como libre e irrestricto para todas las personas que aprobaran la educación secundaria y señalaba la inconveniencia de exámenes eliminatorios u otros mecanismos de exclusión. En la UNC, los cursos de nivelación tienen exámenes no eliminatorios en algunas facultades y están destinados a introducir a los jóvenes y adultos en la dinámica académica universitaria y en los conocimientos básicos principales del área que corresponde a la disciplina que se quiere estudiar.

A partir de esta ley, y una vez que se reglamentó, cada universidad podrá dictar normas sobre la regularidad en los estudios para establecer sus propias condiciones y criterios académicos exigibles. Ante algunas críticas al proyecto, respecto a que cercena la autonomía de las universidades, la diputada Puiggrós

21 Boletín oficial de la República Argentina, Consultado en línea el 11 de noviembre de 2015.

https://www.boletinoficial.gob.ar/\#!DetalleNorma/185524/20180612 
señaló que la misma está garantizada por la propia Constitución Nacional, y agregó que "La autonomía universitaria no quiere decir que las universidades sean extraterritoriales, sino que están bajo la Ley Nacional de Educación y bajo la Constitución Nacional".

Es decir, la historia fue modificando nuevas formas de vida política y social y en ese marco, la universidad, que se fue adaptando a ellas, juega un papel fundamental ${ }^{22}$.

\section{La creación de nuevas universidades nacionales}

Durante el período del gobierno de los Kirchner se establecieron en el país 17 nuevas universidades. Nadie puede objetar esta decisión, aunque muchas de esas creaciones no respondieron a la demanda de diferentes regiones, sino a otros intereses o motivaciones ideológicas, económicas o políticas por encima de las académicas. No es casual que la dirección de ellas quedara en manos de dirigentes o militantes políticos que adherían al kirchnerismo, y quienes no siempre poseían los antecedentes que deben exigirse a un rector. Varias terminaron convirtiéndose en un botín político y fueron utilizadas como auténticas cajas negras para el financiamiento político y se ampararon en la autarquía para no rendir cuentas. A través de esas instituciones, el gobierno nacional desvió fondos para ejecutar obras inexistentes, subejecutadas o sobrevaluadas ${ }^{23}$. En esa etapa fue moneda corriente el envío de dinero desde el Ministerio de Planificación a distintas universidades con el propósito de crear distintos programas, para lo cual terminaban subcontratando empresas amigas de funcionarios por montos excesivos.

Por otra parte, esta política generó un problema extra, en especial en la provincia de Buenos Aires, pues a medida que se crearon estas universidades que veían crecer sus presupuestos, la UBA, que tiene más de 300.000 estudiantes fue recibiendo cada vez un porcentaje menor del presupuesto nacional. En los últimos 7 años del gobierno kirchnerista pasó del 31\% del presupuesto universitario total a solo el $28 \%{ }^{24}$.

Otro riesgo es que estas universidades, recientemente creadas y acostumbradas a recibir el envío de recursos a través de distintos ministerios, en el futuro puedan tener problemas de financiamiento, lo que genera incertidumbre y, a su vez, la probabilidad de que terminen dividiendo a las universidades en las de primera calidad y las periféricas.

22 www.uader.edu.ar/wp-content/.../Breve-reseña-de-la-ley-modificatoria-de-la-LES.

23 Tal el caso, por ejemplo, de la Universidad Tres de Febrero que usó el dinero para la contratación de artistas, o la de General Sarmiento que firmó un convenio de cooperación por más de 5 millones de pesos con la AFSCA con el objeto de desarrollar un programa de formación en comunicación popular destinado a promover la comunicación audiovisual en organizaciones sociales. Por su parte la Facultad de Periodismo y Comunicación Social de la Universidad de La Plata recibió 2,9 millones de pesos para un programa denominado: "Ellas hacen, ellas dicen".

24 La Nación, 9 de octubre de 2016, "Editorial", 34 col 1 y 2. 
Lo cierto es que hoy tenemos carreras sobredimensionadas, que registran, año tras año, un crecimiento de la matrícula, pero al mismo tiempo carreras estratégicas con bajos ingresos.

Marcela Mollis se preguntó si la política kirchnerista con un ingreso irrestricto es inclusión social o expansión de la oferta. Tema difícil de resolver con una respuesta corta. De todos modos, la situación no difiere de otras de América Latina donde la dimensión de la desigualdad regional es una expresión de las desigualdades educativas y se refiere a las diferencias en la educación ofrecida y demandada entre las diversas áreas geográficas, entre el medio rural y el medio urbano, entre las grandes ciudades, las capitales departamentales y las ciudades menores en términos de indicadores de calidad, de cantidad, de diversidad, y de pertinencia ${ }^{25}$.

\section{Retos y perspectivas de la Universidad en el siglo XXI}

En estos últimos años infinidad de especialistas y rectores de universidades nacionales han hecho hincapié en el tema de los desafíos de la Universidad argentina en el nuevo siglo ${ }^{26}$. El mismo es también preocupación de la agenda del Ministerio de Educación, Ciencia y Tecnología, a través de la Secretaría de Políticas Universitarias, y del Consejo Interuniversitario Nacional [CIN], con sus acuerdos plenarios que dan cuenta de las transformaciones universitarias y el Consejo de Rectores de Universidades Privadas [CRUP] que se preocupan por analizar como la Universidad enfrenta los problemas de la educación superior en los escenarios globales de la internacionalización. También en esa búsqueda de analizar los cambios, dinámicas y los conflictos y desafíos actuales debemos mencionar varios encuentros sobre la Universidad, como objeto de investigación, impulsados por el Dr. Pedro Krostch y la creación de una red, que fue conformando un campo creciente de temas de interés e incrementaron la bibliografía de la que nos hemos valido para reseñar estas líneas ${ }^{27}$.

A continuación, nos proponemos enumerar y desarrollar algunas de las problemáticas centrales que, en el siglo XXI, atraviesa a la educación superior argentina, las que, en algunos casos, no difieren de la situación latinoamericana ${ }^{28}$.

En el año 2018 la Argentina festejo el centenario de la Reforma Universitaria, un acontecimiento de gran repercusión en el país, pero fundamentalmente en toda América Latina. Y entonces, debemos preguntarnos ¿cuál es el reto actual de esta Universidad y cuáles sus perspectivas?

Las instituciones de estudios superiores en América Latina superan las 11.000 y ellas son de diversas identidades y características. Paralelamente, la República

25 C. Rama y Marcelo Cevallos, "Nuevas dinámicas de la regionalización universitaria en América Latina”. Magis, Revista Internacional de Investigación en Educación, 8 -17, (2016): 99-134. http://dx.doi.org/10.11144/Javeriana.m8-17.ndru, consultado en línea en 2016.

26 Entre otros, el de Fernando Tauber, 2010, Discurso de asunción a la Presidencia de la UNLP, período 2010-2014. www.unlp.edu.ar/ uploads/docs/la_universidad_argentina_en_el_bicentenario. Consultado en línea 2016.

27 Adrián Acosta Silva... [et.al.]. Los desafíos de la universidad pública en América Latina y el Caribe / - 1a. ed. - Ciudad Autónoma de Buenos Aires, CLACSO, 2015. E-Book. - (Red CLACSO de posgrados).

28 C. Rama, La tercera reforma de la educación superior en América Latina. (Buenos Aires, Fondo de Cultura Económica, FCE, 2006). 
Argentina cuenta con más de un centenar de universidades, 50 estatales y 50 privadas y varias extranjeras distribuidas en todo el territorio con diferentes dimensiones, calidades, formas de gobierno y plantel docente.

La Universidad Nacional de Córdoba posee una matrícula de 130.000 estudiantes de diversas procedencias en tanto su influjo sigue siendo grande en la región, pues asiste a 250 carreras de grado, posgrado y doctorado en 15 Facultades. La oferta académica también incluye 100 centros de investigación y servicios, 25 bibliotecas, 16 museos y se ejecutan 1500 proyectos de investigación y vinculación. Hay, además, en la provincia una Universidad Tecnológica Nacional y dos Universidades nacionales en el interior en las ciudades de Villa María y Río Cuarto, además de varias universidades privadas. Estos indicadores señalan el peso que tiene la educación superior en la provincia.

\section{Las funciones básicas de la Universidad}

Las tres funciones básicas de la universidad son: Enseñanza, Investigación y Extensión. A continuación, las abordo brevemente.

\section{Enseñanza: ingreso irrestricto y deserción}

Con respecto a la enseñanza, Argentina tiene un problema con el ingreso irrestricto. Por eso, según algunos autores el derecho a la educación superior debería planificarse, porque de cada 10 estudiantes inscritos solo 3 llegan a graduarse, la mitad abandona en los tres primeros años. Algunos rectores preocupados por el tema de la deserción han construido modos de garantizar la inclusión con calidad, definiendo formas diversas y creativas de acceder a la universidad a partir de claros problemas de formación en el nivel secundario, y atendiendo a diferentes perfiles de ingresantes se dictan cursos de nivelación.

Mónica Marquina, una estudiosa del tema, sostiene que no solo deben tomarse medidas pensando en el ingreso para todos, sino pensar que el derecho a la educación superior implica transitar y salir con un título que tenga igual valor como cualquier otro ${ }^{29}$. Está más que demostrado que el ingreso irrestricto per se no asegura democratización de la universidad, y los problemas se trasladan al futuro.

De todos modos, mi trayectoria en el sistema universitario argentino me ha llevado durante muchos años a transitar espacios de enseñanza como docente de cursos de primer año y eso me ha permitido convencerme de que el acceso a las aulas universitarias siempre trasmite conocimientos y cultura, al tiempo que es enriquecedor para todos los jóvenes y más aún, para los que no se gradúan.

La universidad pública argentina se ha caracterizado por ser un espacio de convergencia de distintos sectores sociales, lo que genera la posibilidad de movilidad social a los sectores medios y la ilusión de "mi hijo doctor", sueño de muchos padres inmigrantes no letrados a comienzos del siglo $\mathrm{XX}$, se mantiene. Hoy familias obreras iletradas ven con orgullo que uno de sus miembros termine una carrera universitaria.

29 Pablo Buchbinder y Mónica Marquina, Masividad, heterogeneidad y fragmentación. El sistema argentino 1983-2008, (Universidad General Sarmiento, 2008). Adriana Chiroleu, Mónica Marquina y Eduardo Rinesi (compiladores) La política universitaria de los Kirchner: continuidades, rupturas. Complejidades, (Universidad Nacional de General Sarmiento, Los Polvorines, 2012). 
Los planes de estudio de algunas carreras suponen alumnos de dedicación exclusiva, sin embargo, no todos pueden cursar 4 materias en un cuatrimestre. Hay que tener en cuenta la situación económica de muchos jóvenes que terminan el secundario y no pueden hacer frente a los gastos que implica la universidad. Si bien los estudios son gratuitos, hay que pagar apuntes, libros, transporte, etc. En la gran mayoría de casos, esos jóvenes deben también trabajar muchas horas para mantenerse y se vuelve imposible cumplir las metas académicas, entonces tras repetir varios años, abandonan por cansancio ${ }^{30}$. También se ha dicho que una de las causas de deserción es la mala elección de la carrera, decisión que los jóvenes la toman en el verano en que han concluido sus estudios secundarios, sin tener en cuenta el esfuerzo que implica cursar algunas carreras para las que no están preparados.

Por otro lado, hay que señalar que la universidad gratuita es sobreutilizada por los sectores socioeconómicos más pudientes. El 50\% de los jóvenes del sector más acomodado de la sociedad asiste a la universidad pública, contra solo el 10\% del más bajo. Muchas veces aquellos jóvenes provienen de escuelas secundarias muy bien pagas, siendo la preeminencia femenina en las aulas de la UNC cada vez más marcada ${ }^{31}$. Al respecto, Marcelo Rabossi, investigador de la Universidad Di Tella, ilustra:

"El ingreso irrestricto se presenta como un sistema igualitario, pero no lo es tanto. Los alumnos universitarios de los sectores más pobres tienen el doble de probabilidad de abandonar los estudios antes de graduarse que los de los sectores más ricos. Entonces, el sistema es democrático -y hasta por ahí nomás- en el ingreso, pero selectivo en el egreso" 32 .

Se debe avanzar en el control de la deserción que es producto, entre otras causas, de dificultades socioeconómicas; de la masividad que impide al docente ocuparse de aquellos jóvenes que arrastran deficiencias, porque su secundario ha sido mediocre e incide en la excesiva duración de la formación de grado. Esta mejora permitiría incrementar la cantidad de graduados calificados.

Los alumnos extranjeros que cursan el doctorado, la maestría, o la especialidad han monopolizado muchos postgrados en la Universidad de Córdoba, en tanto abonan una cuota mínima que oscila entre los 30 y 50 dólares mensuales ${ }^{33}$. De todos modos, es necesario consolidar una Universidad inclusiva que asuma

30 El Anuario de Estadísticas de la Universidad Nacional de Córdoba, 2015, ofrece cifras reveladoras cuando analiza la situación académica de la cohorte 2005-2015. Al cabo de diez años la deserción de este grupo fue del 64\%. Otros datos indican que el 10,5\% de los matriculados en el 2005 siguen en la misma carrera, el 3,6\% se cambió a otra, mientras el 31,3\% logró graduarse en la misma facultad a la que ingresó y un $3 \%$ lo hizo en otra carrera.

La Voz del Interior, Córdoba 10 de octubre de 2016, pág. 23. Artículo de Juan Carlos Carranza "La Universidad tiene que estar más cerca".

31 En el 2015, dos de cada tres personas que egresaron en Córdoba eran mujeres. Se recibieron 4837 mujeres contra 2376 varones. El $62 \%$ del alumnado es femenino.

32 Noticias UBA, Clarín, Buenos Aires, 30 de octubre de 2015, Nota Sociedad, 38.

33 El costo de la Maestría es una matrícula + 22 cuotas completas + 11 medias cuotas en el tercer año mientras se realiza la tesis. Daré un solo ejemplo en un Doctorado sobre Relaciones Internacionales que se dicta en la Universidad de Córdoba de 120 alumnos, hay uno solo de Córdoba, 3 provienen de las provincias de la Rioja y 3 de Catamarca, el resto son extranjeros, mayoritariamente colombianos, aunque hay mexicanos, ecuatorianos y brasileros. 
un rol protagónico en la construcción de una sociedad en la que la educación, el conocimiento y los demás bienes culturales se distribuyan democráticamente. Pero eso no excluye la necesidad de planificar y ordenar las inscripciones ${ }^{34}$. En algunas áreas, por ejemplo, podemos saber cuántos ingenieros se necesitan, pero en otros casos no. Por otra parte, según cifras de la Secretaría de Políticas Universitarias, el número de inscriptos y graduados crece más en las universidades privadas que en las estatales. En el año 2001 en las universidades nacionales había una población de 2.174.672 educandos y, según el Censo de población de 2010, ese número se incrementó a 3.363.119 estudiantes ${ }^{35}$.

Otro ítem para tener en cuenta en la enseñanza es la situación de los docentes. Este aspecto requiere:

- Incrementar en forma significativa la cantidad de docentes por cátedras, habida cuenta la matricula masiva y mejorar sus salarios o dedicaciones.

- Promover la formación de doctores integrantes de su sistema de investigación básica y aplicada.

- Consolidar la vinculación interuniversitaria, promoviendo la conformación de redes científicas, la movilidad de alumnos, docentes e investigadores, la homologación de títulos y las investigaciones conjuntas, aprovechando la cooperación internacional y priorizando la integración latinoamericana, particularmente con el MERCOSUR.

Al respecto, en octubre de 2016 Ernesto Samper - expresidente de Colombia y actual Secretario General de la Unión de Naciones Suramericanas (UNASUR)organismo que nuclea a los países de América del Sur, disertó en dos universidades nacionales, entre ellas en la de Córdoba, sobre "Sudamérica: los desafíos y potencialidades de una región de paz para avanzar en los caminos del desarrollo". Y definió como fundamental el papel de la educación superior en el proyecto de ciudadanía suramericana. En relación con el papel de las universidades en la región, el exmandatario puntualizó:

"La integración no se refiere, únicamente, a que puedan circular las mercancías, sino también las personas. Por eso, dentro del proyecto de ciudadanía suramericana, uno de los aspectos fundamentales es la creación de un espacio de educación superior común" ${ }^{\prime 36}$.

En este sentido, puntualizó que junto a la mayor movilidad de estudiantes y profesores y a la conformación de redes de investigación científica, el reco-

34 Como parte de los resultados del Proyecto MISEAL se ha desarrollado una formación a nivel posgrado en Estudios en Inclusión, Interseccionalidad y Equidad (ESIINE) entre Instituciones de Educación Superior. ESIINE asume una perspectiva teórico-metodológica para formar a profesionales capaces de analizar e investigar las dimensiones múltiples de la exclusión social y de la inequidad. Asimismo, asume el hecho de que la universidad tiene que transformarse, incorporando diversas formas de conocer y situarse en el mundo para generar nuevos saberes que rompan con los esquemas excluyentes. ESIINE es una especialización transnacional que favorecerá el intercambio de profesores, investigadores y estudiantes entre instituciones de educación superior de América Latina y de la Unión Europea, dando lugar al desarrollo de líneas de conocimiento y de investigación conjuntas que contribuyan a mejorar la calidad de la educación.

35 Estela M. Miranda, Democratización... op. Cit. 122. Raquel San Martín, "De los deseos a lo real. La Universidad en debate "en La Nación, Buenos Aires, 5 de junio de 2016, Suplemento Ideas 5.

36 Entrevista a Ernesto Samper en La Voz del Interior, 9 de octubre de 2016, periódico de Córdoba. 
nocimiento de los títulos profesionales en los distintos países es una cuestión fundamental.

\begin{abstract}
"Nuestra meta es llegar a que cualquier estudiante pueda iniciar su carrera en Colombia y terminarla en Argentina; que un médico boliviano pueda ejercer su profesión en Chile; que un profesor que está habilitado para una determinada materia en Venezuela pueda enseñar en Uruguay y expresó: queremos crear ese espacio de educación superior y, para ello, una universidad como ésta, joven y con un claro sentido social, resulta muy importante" ${ }^{\prime 37}$.
\end{abstract}

\title{
La Investigación
}

Las actividades de Ciencia y Técnica en las universidades argentinas se realizan generalmente en las Facultades que, usualmente, tienen posibilidad de financiar, evaluar y coordinar esas actividades a través de sus Secretarías de Ciencia y Técnica. La práctica más frecuente es el desarrollo de un proyecto en cátedras o en institutos de investigación creados para desarrollar investigaciones específicas. Lamentablemente no es usual la colaboración de equipos provenientes de las distintas universidades nacionales. El programa de Incentivos del Ministerio de Educación de la Nación incrementó la formación de equipos, generalmente, conformados por un director, que puede o no pertenecer a CONICET, con un promedio de tres o más docentes investigadores de menor rango.

Otro canal de investigación relacionado con la universidad es el que presta el CONICET - Consejo Nacional de Investigaciones Científicas y Técnicas- que desde 1958 encarna la investigación científica y tecnológica en la percepción social, en tanto es el organismo que tiene el mayor reconocimiento de la población, la mayor valoración de pares y el que acumula mejores resultados, dentro del sistema científico y tecnológico que integran además las universidades. Con la creación del Ministerio de Ciencia, Tecnología e Innovación Productiva, en diciembre de 2007 la ciencia adquirió un rol clave en la estructura económica argentina. A través de la Dirección Nacional de Relaciones Internacionales se creó el Programa RAICES (Red de Argentinos Investigadores y Científicos en el Exterior) que se proponía la repatriación de recursos humanos que, por distintos motivos, estaban en el exterior. En 2008 el programa fue declarado política de Estado por la Ley № 26.421. Hasta hoy han regresado al país más de 1130 científicos, quienes fueron ubicados en las universidades nacionales y privadas, en institutos asociados a CONICET o en empresas privadas.

También son dignos de destacar institutos como el INTI (Instituto Nacional de Tecnología Industrial), el INTA (Instituto Nacional de Tecnología Agropecuaria) y las Agencias encargadas de concursar y financiar parcialmente proyectos específicos de innovación con distintas normativas, en general derivadas de los criterios de asignación de créditos internacionales (cooperación de privados, participación de investigadores de más de una universidad u otros). Ello posibi-

37 Ibídem. 
litó que Argentina destine aproximadamente el 5,4\% de su PBI a la educación, porcentaje que no llega a la mitad del adoptado como recomendable.

A pesar de los problemas de financiamiento, la investigación realizada en sus universidades hizo posible que Argentina contara con cinco premios Nobel, tres por los hallazgos realizados en el ámbito de la salud: dos en Medicina, uno en Química y otros dos en otro importante campo de dichos premios: la Paz. El Dr. Carlos Saavedra Lamas y Adolfo Pérez Esquivel, Licenciado en Bellas Artes y doctor en arquitectura y urbanismo, recibieron ese galardón en 1936 y en 1980, respectivamente.

\section{La extensión}

La tercera función universitaria es la extensión que es considerada desde la época de la reforma de 1918, en el contexto de las universidades nacionales, como una de las funciones esenciales, que conjuntamente con la investigación y la docencia constituyen los pilares básicos sobre los que se construye un modelo de universidad democrática y comprometida socialmente en búsqueda de la excelencia y la equidad social.

En los últimos años, los trabajos de extensión han crecido desde distintas cátedras y facultades con el fin de desarrollar políticas de articulación con todo el sistema educativo para facilitar el tránsito del nivel medio a la educación superior, colaborando en la formación de sólidas bases cognitivas y de aprendizaje en los niveles precedentes, de tal manera que los ingresantes cuenten con los valores, habilidades, destrezas y capacidades para poder adquirir, construir y transferir conocimientos en beneficio de la sociedad y para desarrollar sus carreras ${ }^{38}$.

\section{Universidad, sociedad y sectores productivos}

Para finalizar, daremos un repaso al tema de relación entre la Universidad y los sectores productivos. La relación universidad-empresa no es nuevo en $\mathrm{Ar}$ gentina, incluso hay quienes piensan que el mismo puede rastrearse desde 1930, aunque entonces ella se realizaba de manera informal.

En la Universidad de Córdoba a comienzos de la década de 1960, el gobierno del presidente Arturo Illia puso el acento en el nacionalismo económico, la industrialización, la distribución del ingreso y la garantía de los derechos sociales. Entre otras medidas, dispuso el control de precios de los alimentos y de los medicamentos en el marco de una política económica que buscó fortalecer el pleno empleo con intervencionismo social, mercados protegidos, e industrialización por sustitución de importaciones. Un ejemplo de ello fue la donación de fondos reservados del Poder Ejecutivo, en 1963, para la creación del Laboratorio de Hemoderivados de la Universidad Nacional de Córdoba, el cual debía tener un claro objetivo social: la producción de medicamentos a bajo costo que sustituyera importaciones y regulara los precios del mercado.

38 Patricio Alberto Cullen, Universidades para el siglo XXI, edUTecNe Buenos Aires, 2009.http://nulan.mdp.edu.ar/1239/1/01152.pdf, consultado en octubre de 2016. 
En los años '80 del siglo pasado, infinidad de artículos comienzan a instalar la cuestión en la agenda de las políticas universitarias y la vinculación universidad-empresa aparece como necesaria para la modernización de los países latinoamericanos. En este último tiempo la frondosa bibliografía se ha incrementado tanto en los países desarrollados como en los subdesarrollados.

Concretamente en la Argentina, la sanción de la ley Nro. 23877 de Promoción y Fomento de la Innovación Tecnológica, reglamentada en 1992, facultaba la creación de unidades de vinculación como órganos externos a las universidades. A partir de entonces, se establece dicha figura como una iniciativa para vincular la ciencia y la tecnología con la producción ${ }^{39}$. A diferencia de lo ocurrido en años anteriores, ahora la universidad tiene un mayor grado de formalización de relaciones con todas las disciplinas abarcando más áreas de conocimiento. Simultáneamente el Estado está más involucrado con los sectores productivos y estos a medida que la producción se vincula más estrechamente con las tecnologías nuevas, tienen una relación más estrecha con la investigación científica. A comienzos del siglo XXI y teniendo en cuenta que la sociedad del conocimiento demanda nuevas formas organizacionales y que en este escenario el concepto innovación alcanza una dimensión más amplia, la valorización de la universidad mejora pues ella debe asumir un rol activo en el proceso de desarrollo ${ }^{40}$.

En todas las universidades nacionales argentinas surgieron varios programas y once de ellas cuentan con proyectos de polos o parques tecnológicos e incubadoras de empresas. A modo de ejemplo podríamos mencionar la Planta Piloto de Ingeniería Química dependiente de la Universidad del Sur o la experiencia y desarrollo minero de la Universidad de San Juan, entre otros ${ }^{41}$. La Universidad del Litoral tiene un proyecto de cooperación con el centro de transferencia de tecnología de la Universidad de Valencia. Y la de Córdoba, desde 1996, realiza trabajos a terceros, particularmente desde las unidades académicas de ciencias duras. ¿Cuáles son los problemas que esto trae? -Que, a veces, la falta de registros públicos dificulta cuantificar esta relación debido a que los convenios de transferencia se realizan por medio de fundaciones privadas o cooperadoras y no hay control por parte de los Consejos universitarios.

39 En virtud de ello, por ejemplo, la universidad de Buenos Aires instaura la Dirección de Convenios y Transferencias de Tecnología que cuenta con un nodo en cada Facultad y en torno a ello se firmaron cientos de convenios.

40 J.C. Pugliese., (Ed.) Universidad, sociedad y producción, (Ministerio de Educación, Ciencia y Tecnología, Secretaría de políticas públicas, Buenos Aires, 2004).

41 Judith Sutz Universidad- sectores productivos, Centro Editor de América Latina, Buenos Aires 1993. Mariana Versino y otros, Universidades y sociedades, aproximaciones al análisis de la vinculación de la Universidad con los sectores productivos, (Universidad Nacional General Sarmiento, Buenos Aires 2012), capítulo tercero, 55 y ss. 


\section{CONCLUSIÓN}

Para concluir y a riesgo de simplificar podemos señalar:

1. Las universidades argentinas conforman un conjunto complejo y diferenciado de instituciones, tradiciones y proyectos, contando con más de tres millones de alumnos. En estos últimos años el ingreso se ha quintuplicado, aunque su evolución pone en evidencia que hay una brecha grande entre ingreso y egreso. Para algunos especialistas, la universidad es una institución científica que debe medirse con estándares internacionales; para otros, es un espacio eminentemente político que enfrenta múltiples dificultades.

2. Después de hacer el recorrido histórico concluimos que la universidad de Córdoba, de gran tradición y con cuatro siglos de historia, arrastraba en el siglo XX algunos problemas que fueron señalados tempranamente por los estudiantes de la reforma de 1918 tales como la autonomía, la libertad de cátedra, los concursos docentes, etc.

3. La presencia de gobiernos autoritarios después de golpes militares y especialmente durante las dictaduras militares del siglo XX echaron por tierra esos postulados y modificaron las normativas, lo que trajo nefastas consecuencias a docentes y estudiantes opositores.

La agenda de las últimas décadas de este estudio mantuvo como prioritarias las siguientes cuestiones:

a- El tema del ingreso libre versus ingreso restricto,

b- Calidad, equidad y eficiencia en las funciones de la universidad: capacitación profesional, investigación y extensión.

c- El problema del financiamiento. En el siglo XXI la casa de altos estudios de Córdoba enfrenta nuevos retos que, a veces, no puede resolver por contar con un presupuesto ajustado para atender la demanda de sus más de ciento treinta mil estudiantes. Por otra parte, este es un tema que afecta hoy del mismo modo al resto de las universidades nacionales y de la región.

4. Sin embargo, quiero destacar que a pesar de todos los problemas descritos, la República Argentina es el país de América Latina que cuenta con cinco premios Nobel egresados de sus aulas universitarias y que hoy muchos de sus científicos están haciendo punta en diversas especialidades en el mun$\mathrm{do}^{42}$. Y a pesar de las críticas que puede hacérsele a la universidad hay que señalar que ella acoge en su seno a los investigadores de CONICET quienes, en estos últimos años, aumentaron su producción y solidificaron redes de

42 Al respecto daré sólo tres ejemplos de egresados destacados de la Universidad de Córdoba: Gabriel Rabinovich, Dr. en Bioquímica, por sus estudios sobre el cáncer recibió el premio al mejor investigador en medicina 2010 de la Academia de Ciencias para el Mundo en Desarrollo [Twas, sus siglas en inglés]. Gabriela González, física, premiada por la Academia de Ciencias de EEUU y postulada en el 2016 para el premio nobel con otros investigadores norteamericanos por sus descubrimientos en las ondas gravitacionales, que formaban parte de la obra teórica que Albert Einstein elaboró hace 100 años, abrió una nueva ventana en la Astronomía. Y un grupo de científicos cordobeses lograron un importante avance en el tratamiento contra el cáncer de mama a partir de nanotecnología, desarrollando un nuevo proceso para suministrar una droga que resuelve los problemas de los tratamientos oncológicos actuales: minimiza los efectos tóxicos y mejora la efectividad de la terapia al transportar el agente activo directamente al tumor. 
investigación científica. A la vez crecieron sus posgrados y un organismo como la Comisión Nacional de Evaluación y Acreditación Universitaria [CONEAU] procura velar por la calidad académica y gestión de las altas casas de estudio.

5. En síntesis, la universidad argentina y la de Córdoba en particular, acompañan el desarrollo social del Estado y la búsqueda de nuevos conocimientos desde el siglo XVII hasta hoy, enfrentándose a nuevos retos, innovaciones. y perspectivas. Esto demuestra que la misma no está paralizada.

\section{FUENTES}

“El Manifiesto Liminar", La Gaceta Universitaria, Córdoba, viernes 21 de junio de 1918, año I, Nro.10. Boletín Oficial de la República Argentina. Distintos años.

Encuentros de la Universidad como objeto de investigación. Universidad de Buenos Aires 1995 y 1997,

Universidad de La Plata 2002, Universidad de Tucumán 2004, Universidad del Centro de la provincia de Buenos Aires 2007, Universidad de Córdoba 2009. Universidad de San Luis 2013. Universidad del Litoral 2017.

Declaración de la CRES, Córdoba, Argentina, 14 de junio de 2018. Consultada en línea. http://www. cres2018.org/biblioteca/declaracion-final-cres-2018.

La Carcajada, periódico cordobés, 5 de junio de 1881.

Noticias UBA, Clarín, Buenos Aires, 30 de octubre de 2015, Nota Sociedad, p. 38.

La Nación, 9 de octubre de 2016, “Editorial". 34 col 1 y 2.

La Nación, Buenos Aires, 5 de junio de 2016, Suplemento Ideas 5. SAN MARTIN Raquel, “De los deseos a lo real. La Universidad en debate".

La Voz del Interior, Córdoba 10 de octubre de 2016, pág. 23. Artículo de Juan Carlos Carranza “La Universidad tiene que estar más cerca".

La Voz del Interior, 9 de octubre de 2016, Córdoba. Entrevista a Ernesto Samper.

Revista Flecha, Córdoba, 15 de junio de 1936.

\section{REFERENCIAS}

Alaniz, María y otros, en "Las reformas educativas en las universidades públicas" en Movimientos estudiantiles en América y Europa, Córdoba, Junta Provincial de Historia de Córdoba, Báez Ediciones, 2006, Tomo II.

Acosta Silva, Adrián ... [et.al.]. Los desafíos de la universidad pública en América Latina y el Caribe / 1a. ed. - Ciudad Autónoma de Buenos Aires, CLACSO, 2015. E-Book. - (Red CLACSO de posgrados).

Buchbinder, Pablo - Marquina Mónica, Masividad, heterogeneidad y fragmentación. El sistema argentino 1983-2008, Universidad General Sarmiento, 2008.

Carcano, Ramón J., La Universidad de Córdoba. Algunas palabras sobre su organización, Buenos Aires, Félix Lajoune, 1892.

Coraggio, José Luis y Vispo, Adolfo [Edit], Contribución al estudio del sistema universitario argentino, Buenos Aires, Miño y Dávila editores 2001.

Cullen, Patricio Alberto, Universidades para el siglo XXI, edUTecNe Buenos Aires, 2009. http://nulan. mdp.edu.ar/1239/1/01152.pdf,

Daros, W. Incidencias del proceso histórico en el proceso educativo argentino. Revista Historia de la Educación Latinoamericana, vol. 16 no. 22 (2014): 51-84. https://doi. org/10.19053/01227238.2689 
De La Mata, Gabriela, (editora) La Universidad argentina en el cambio de siglo, Buenos Aires, Jorge Baudino, 2004.

Gomez, Alejandra, No nos han vencido..., Historia del Centro de Estudiantes de Derecho UBA, Librería del Centro de Estudiantes, UBA, Buenos Aires, 1994.

Gvirtz, Silvina y CAMOU Antonio, con la colaboración de Diego Santori, La Universidad argentina en discusión: sistema de ingreso, financiamiento, evaluación de la calidad, y relación universidad Estado, 1era. edición, Buenos Aires, Gránica, 2009.

Kohan, Néstor, Deodoro Roca, el hereje, selección y estudio preliminar. Buenos Aires, Editorial Biblos, 1999.

Miranda, Estela M. (coordinadora), Democratización de la educación superior. Una mirada a 400 años de la Universidad en la región, I Seminario de Democratización de la Educación Superior. Una mirada desde el MERCOSUR, Universidad Nacional de Córdoba, Córdoba, 2014.

Mollis, Marcela, La universidad argentina en tránsito. Ensayo para jóvenes y no tan jóvenes, FCE, Buenos Aires, 2001.

Pérez Lindo, Augusto, Universidad, política y sociedad. Editorial Eudeba, Buenos Aires, 1986.

Pugliese, J.C., Ed., Universidad, sociedad y producción, Ministerio de Educación, Ciencia y Tecnología, Secretaría de Políticas Públicas, Buenos Aires, 2004.

Rama, Claudio, La nueva reforma de la diversidad universitaria: de la diferenciación institucional a la diversidad educativa, es.slideshare.net/claudiorama/la-nueva-reforma-de-la-diversidad-universitaria

Rama, C., La tercera reforma de la educación superior en América Latina. Buenos Aires, Fondo de Cultura Económica, FCE, 2006.

Rama, Claudia \& Cevallos, Marcelo (2016). “Nuevas dinámicas de la regionalización universitaria en América Latina". MAGIS, Revista Internacional de Investigación en Educación, 8 (17), 99-134. http://dx.doi.org/10.11144/Javeriana.m8-17.ndru

Riquelme, Norma Dolores, "Conformación de espacios de poder en el gobierno de la Universidad Córdoba (Argentina) a mediados del siglo XX", Revista Historia de la Educación Latinoamericana no. 11, (2008), 167 a 188.

Roca, Deodoro, El difícil tiempo nuevo, Ed. Lautaro, Buenos Aires, 1956.

Roca, Deodoro; El drama social de la Universidad, Editorial Universitaria de Córdoba, Córdoba, 1968.

Sanguineti Susana, PEREYRA Marta, Extensión universitaria. Posición ideológica y decisión política al servicio de la comunidad, Editorial Brujas, Córdoba 2016.

Sarlo, Beatriz, La batalla de las ideas 1943-1973, Biblioteca del pensamiento argentino, VII, Emecé, Buenos Aires 2007.

Servetto, Alicia y SAUR Daniel, [Comps] Sentidos de la Universidad, Universidad Nacional de Córdoba, Córdoba, 2011.

Soto Arango, Diana Elvira, Rivadeneira, José Antonio; Duarte Acero, Jorge Enrique y Bernal Villate, Sandra Liliana, La generación del movimiento estudiantil en Colombia. 19101924. Revista Historia de la Educación Latinoamericana, 20, no. 30, (2018): 217-241. doi. org/10.19053/01227238.8056

Suasnábar, Claudio, DEL VALLE Damián... [et al., Comp.] Balance y desafíos hacia la CRES 2018 Marco Antonio Rodrigues Dias ... [et al.]; IEC - CONADU, CLACSO: UNA - Universidad Nacional de las Artes, editado por Lucas Petersen. 1a. ed, Ciudad Autónoma de Buenos Aires, 2018.

Sutz, Judith, Universidad - sectores productivos, Centro Editor de América Latina, Buenos Aires 1993.

Tauber, Fernando, 2010, Discurso de asunción a la Presidencia de la Universidad Nacional de La Pampa, UNLP, período 2010-2014. www.unlp.edu.ar/uploads/docs/la_universidad_argentina_en_ el_bicentenario

Vera De Flachs, María Cristina, Una emigración intelectual: los alemanes de la Universidad Nacional de Córdoba. Centro de Estudios Genealógicos de Córdoba. 4 de septiembre de 1993.

Vera De Flachs, María Cristina "La producción científica de docentes e investigadores alemanes de la Universidad de Córdoba" en Actas de las Novenas Jornadas de Historia del Pensamiento Científico Argentino, FEPAI, Buenos Aires, 2000. 
Vera De Flachs, María Cristina y RIQUELME Norma, “Las ciencias y el evolucionismo en el pensamiento de Sarmiento", en Boletín de la Facultad de Filosofía y Humanidades, Universidad Nacional de Córdoba, 1989.

Vera De Flachs, María Cristina, "Reformas y contrarreformas y movimientos estudiantiles en la Universidad de Córdoba, 1870-1936", en Renate Marsiske (Coord.) Movimientos estudiantiles en la historia de América Latina, III, Universidad Nacional Autónoma de México, México, 2006.

Vera De Flachs, María Cristina, "Reflexionando sobre la autonomía en la universidad argentina, 1885-1955" Diana Soto Arango, María Isabel Lafuente Autonomía y Modelos Universitarios en América Latina, España, Tunja, Universidad de León, Búhos Editores 2007.161.

Vera De Flachs, M. Cristina y Sillau Pérez Antonio, “Ideología y Política. Docentes y estudiantes en el contexto de la crisis liberal Argentina. El caso de Córdoba (1930-1943)", Revista Historia de la Educación Latinoamericana, vol. 12, (2009), 247-273.

Vera De Flachs, M. Cristina y De Sierra Teresa, “Tendencias y retos de dos universidades públicas latinoamericanas: (UNAM Y UNC) ante las nuevas políticas públicas para la educación superior", EDUCAÇÃO/PUCRS, Pontifícia Universidade Católica de Rios Grande do Sul, Campinas 2012.

Vera De Flachs, M. Cristina y De Sierra Teresa, "Similares agendas de políticas educativas de dos universidades latinoamericanas: UNC Y UNAM y sus efectos en la consolidación de nuevas identidades, Cuadernos del CIAN, Universidad Carlos III de Madrid, 2012.

Versino, Mariana y otros, Universidades y sociedades, aproximaciones al análisis de la vinculación de la Universidad con los sectores productivos, Universidad Nacional General Sarmiento, Buenos Aires, 2012, capítulo tercero.

Cómo citar:

Vera de Flachs, María Cristina. "Contribución al estudio de la educación superior de la República Argentina. Un recorrido a través de la Historia de la Universidad Nacional de Córdoba" Revista Historia de la Educación Latinoamericana. Vol. 21 No. 32 (2019): 85-107

https://doi.org/10.19053/01227238.9382

(c) (1)@@ Esta obra está bajo una licencia Creative Commons. Reconocimiento-No Comercial-Sin Obra Derivada 2.5 Colombia. 


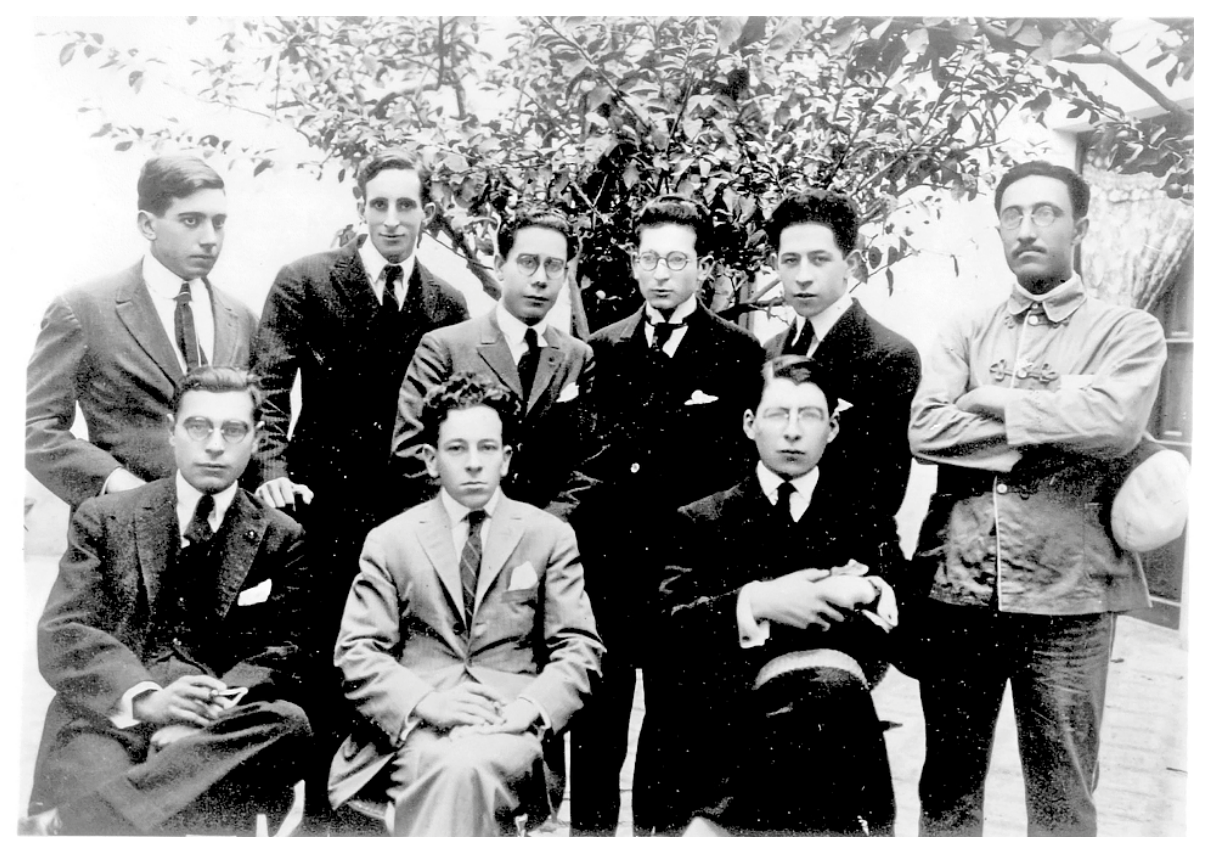

Estudiantes universitarios de Córdoba en tiempos de la Reforma de 1918. Foto propiedad de la autora

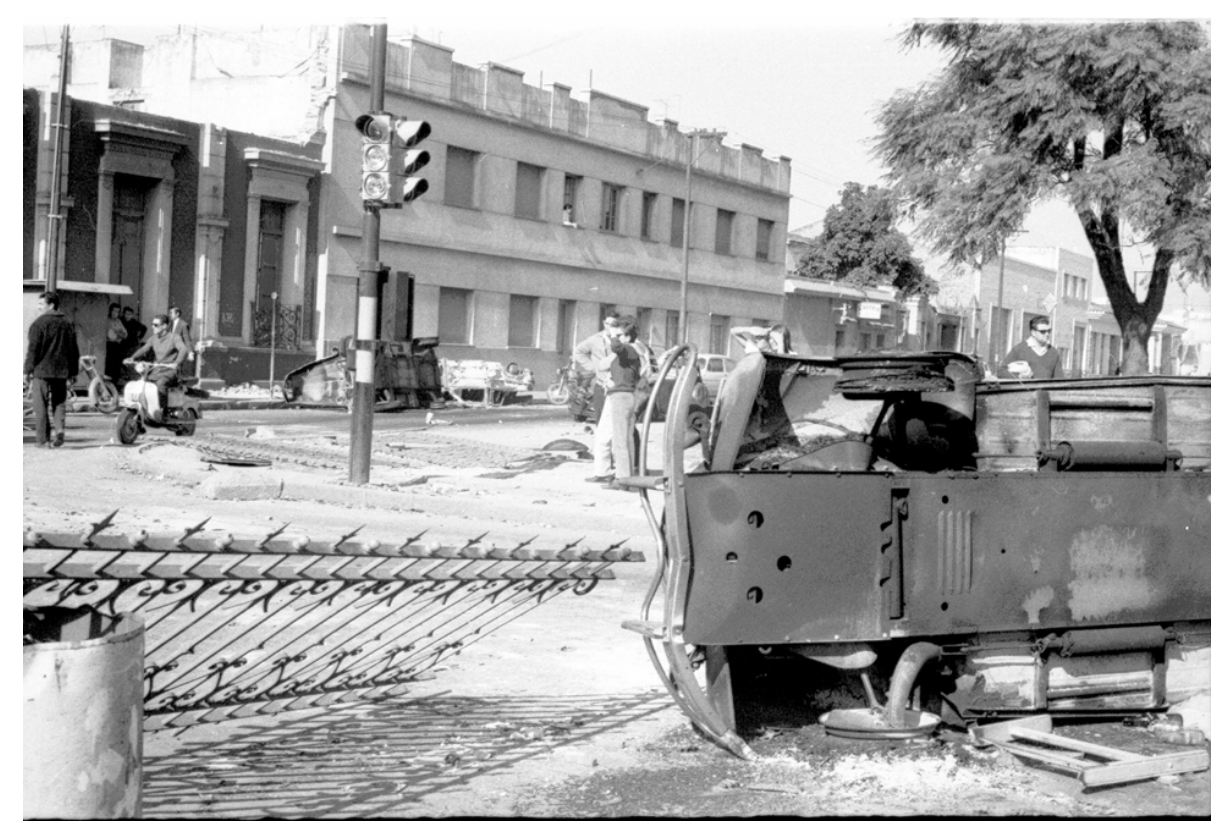

Barricada levantada por estudiantes y obreros en calles de la ciudad de Córdoba en época del Cordobazo, movimiento que enfrento la dictadura del General Onganía. Mayo de 1969. Foto de Noemí de Villafañe Lastra, propiedad de la autora. 